Composites Part A: Applied Science and Manufacturing

Volume 38, Issue 11, November 2007, Pages 2366-2373

\title{
EXPLORING MECHANICAL PROPERTY BALANCE IN TUFTED CARBON FABRIC/EPOXY COMPOSITES
}

\author{
Giuseppe Dell'Anno ${ }^{1 *}$, Denis D Cartié ${ }^{1}$, Ivana K Partridge ${ }^{1}$ and Amir Rezai ${ }^{2}$ \\ 1 - Composites Centre, Department of Materials, Cranfield University, Cranfield, Bedford, MK43 0AL, \\ $\mathrm{UK}$ \\ 2 - BAE Systems, Advanced Technology Centre, Filton, Bristol BS34 7QW, UK \\ *Corresponding author \\ E-mail: g.dellanno@cranfield.ac.uk \\ Tel. $\quad+441234750111$ ext. 2379 \\ Fax $\quad+441234752473$
}

\begin{abstract}
The paper details the manufacturing processes involved in the preparation of through-the-thickness reinforced composites via the 'dry preform - tufting - liquid resin injection' route. Samples for mechanical testing were prepared by tufting a 5 harness satin weave carbon fabric in a $3 \mathrm{~mm} \times 3 \mathrm{~mm}$ square pitch configuration with a commercial glass or carbon tufting thread, infusing the reinforced preforms with liquid epoxy resin and curing them under moderate pressure. The glass thread reinforcement increases the compression-after-impact strength of a $3.3 \mathrm{~mm}$ thick carbon fabric laminate by $25 \%$. The accompanying drop-downs in static tensile modulus and strength of the same tufted laminate are below $10 \%$. The presence of tufts is also shown to result in a significant increase in the delamination crack growth resistance of tufted double-cantilever beam specimens and has been quantified for the case of a $6 \mathrm{~mm}$ thick tufted carbon non-crimped fabric (NCF)/epoxy composite.
\end{abstract}

Keywords

(A) 3-dimensional reinforcement, (A) polymer matrix composites (PMCs), (E) preform, tufting. 


\section{Introduction}

Tufting is a relatively novel technique for achieving through-the-thickness reinforcement in thermosetting polymer matrix composites. It is ideally suited to load bearing structures intended to be made via the dry-fabric/liquid resin moulding processes. The process involves the insertion of a threaded needle into a loose dry fabric or bindered preform and its removal from the fabric along the same trajectory (see Fig.1). The 'tuft' of thread relies on friction from the fabric itself and/or hold provided by underlying ancillary material (e.g. foam) to remain in place. The loop of thread is not locked in place and, given that the samples are made from woven fabric, any additional crimp due to the insertion of the tufts can be considered insignificant. It is to be noted that the process requires only one-sided access to the piece.

Information available in the published literature is currently limited to technical information on the tufting process itself [1] and to general comparisons of tufting against other forms of stitching [2-4] or other forms of Z-direction reinforcement [5]. There is currently no published database relating to the mechanical performance of tufted composites. In contrast to this, much work has been done in the past on more conventional forms of stitching of fabrics for structural composites and significant amount of information has been generated and published [6-13]. Some problem have been encountered in terms of manufacturing complexity, especially in large composite structures and the crimping effect of the locked stitches appears to result in an unacceptable reduction of the in-plane properties of stitched composites. 
The present paper describes the manufacturing processes involved in the preparation of glass and carbon thread tufted carbon fabric/epoxy resin samples and concentrates on the evaluation of the compression-after-impact (CAI) and of the in-plane tensile properties of the cured composites. Preliminary results of measurement of the delamination crack growth resistance of a relatively thick, tufted carbon NCF/epoxy laminate are given.

\section{The tufting process}

The tufting technology is based on the ancient methods of carpet making. The novel aspects involve the development of specialised continuous yarn tufting threads, compatible with the liquid resin moulding type processes for composites manufacture and with the subsequent mechanical and durability performance demands on the final composite. In line with the rising expectation of cost effective manufacturing in the composites industry, the tufting process has been automated. The system used in the present work (see Movie 1) consists of a commercial tufting head (KSL KL150), interfaced to a Kawasaki 6-axis robot arm (FS 20N). The trajectory tracking has been achieved using AS machine programming language designed specifically for use with Kawasaki robot controllers, and the dedicated KCWIN software from Kawasaki.

Figure 2 shows detail of the tufting needle arrangement. The needle diameter is $2 \mathrm{~mm}$. This size is required for robustness of the needle in repeated application but is roughly comparable with the typical 'unit cell' dimensions of a dry continuous fibre preform. If loosely woven dry preforms are used, then the size of the needle seems to pose little problem in term of fibre breakage, as the fibres are able to move out of the way of the needle. However, significant fibre damage can be expected to result in the tufting of highly bindered preforms. The effect of such damage will be a reduction in the in-plane 
strength of the final composite. Our experience to date indicates that knitted fabrics are unsuitable for use with this technology, whilst woven fabrics are relatively easy to tuft and the so called non-crimped-fibre (NCF) fabrics appear ideally suited for tufting.

The machine set up is capable of tufting at rates of up to 500 tufts per minute. Rates up to 250 tufts per minute have been tested successfully in our laboratory on $5 \mathrm{~mm}$ thick bindered preforms, however, all the results reported this study correspond to a tufting rate of 50 tufts per minute. The insertions were orthogonal to the plane of the preform, in a $3 \mathrm{mmx} 3 \mathrm{~mm}$ square tufting pattern. Figure 3 shows the top-side of a tufted preform and the underside loops, revealed after removal of the preform from the support bed. Table1 summarises the attributes of the two commercial threads used in the present work. The 3-yarn glass fibre thread has been used in these types of applications for some time, whereas the particular 2-yarn carbon fibre thread grade used has been developed only recently [14]. The threads were tested for tensile strength in the un-impregnated form, using a Zwick Z010 tensile tester and standard rope specimen grips from Zwick.

The tufts were held in place on the underside of the preform by using an $8 \mathrm{~mm}$ thick silicone based backing layer. Two different materials were utilised: a silicone rubber from Dow Corning $®$ (Silastic $® 3481$ with Silastic $®$ 81T curing agent) or a silicone foam from Samco® (SIL16). The first of these is tougher and guarantees a better grip on the thread whereas the second is cheaper and more suitable for thinner and more 'delicate' threads. An additional nylon film (see Fig. 2) was placed between the dry fabric stack and the silicone rubber or foam bed, to facilitate the removal of the tufted stack from the support prior to the infusion with resin. 
An obvious question arises as to whether the tuft loops should be removed from the panel prior to resin infusion and, if so, how. In the work reported here the tuft loops were left intact, leading to the formation of a thin (under half a millimetre) resin rich layer, containing the flattened tuft loops, on one side of the cured composite panel.

The geometric arrangement of the tufts or blocks of tufts within a panel is an evident process parameter. In this early work we report results obtained by the use of a simple square tufting pattern, with tuft centre-to-tuft centre spacing of $3 \mathrm{~mm}$. This choice was prompted by desire to achieve some form of a comparison with our previous work on Z-pinning of prepreg laminates, in which similar areal densities of the Z-direction reinforcement had been used [15].

\section{Materials and methods}

Samples were made from woven 5 harness satin carbon fibre fabric, $373 \mathrm{gsm}, 6 \mathrm{~K}$ (WEAV-RITE), supplied by Cytec Engineered Materials. The fabric stack was made up from 8 plies of this fabric, arranged as a symmetric $0 / 90^{\circ}$ lay-up. The dry fabric stacks, containing defined regions with and without tufts, were placed in a fixed dimension rectangular flat plate Resin Transfer Moulding tool and infused with Cycom® 977-20 resin under 2 bar pressure. Upon successful completion of the resin fill, the panels were cured in the tool at $180^{\circ} \mathrm{C}$ for 185 minutes. On completion of the cure the nominal panel thickness was $3.35 \mathrm{~mm}$, with a theoretical fibre volume fraction of $50 \%$.

The tensile tests were carried out following BS EN ISO 527-4:1997 standard, on parallel sided $25 \mathrm{~mm}$ wide specimens. The length of the tufted area was selected to be 
longer than the gauge length, with the tabs covering part of the tufted portion of the specimen. At least six specimens were tested for each sample type and the average strength was evaluated by taking into account only those specimens which failed within the gauge section. The 'top side' (no loops) specimen surface was spray-painted with a speckle pattern of black dots on a white background in order to obtain a full strain field measurement via a LIMESS GmbH Digital Image Correlation system [16]. Two 1.4 Mega Pixels digital cameras, operating at a fixed frequency, monitored the displacement of the random dots. In the post-processing stage, image correlation algorithms calculate the strain maps by comparing successive images and following the evolution of the displacement of the dots. The average strain was measured over the central area of the gauge section of the specimen in order to minimise any edge effect.

Compression after impact tests were carried out on $102 \times 152 \times 3.35 \mathrm{~mm}$ specimens. All of these specimens were obtained from a single infused panel, thus ensuring that they all had the same thickness, fibre volume fraction and cure history. There were control specimens and specimens containing a $50 \mathrm{~mm} \times 50 \mathrm{~mm}$ central square block of tufts (GF or CF) with a $3 \mathrm{~mm} \times 3 \mathrm{~mm}$ pattern. This size of the tufted area was selected so that the damage area due to impact did not extend beyond the tufted region. They were clamped at four points according to the Boeing BSS7260 standard for CAI and pre-impacted at a single energy level of $15 \mathrm{~J}$, with the $20 \mathrm{~mm}$ diameter hemispherical impactor of a Rosand Instrumented Falling Weight System. They were then C-scanned prior to being subjected to compression within a Boeing CAI test fixture. Three or four specimens were tested in each case. The C-scan is able to indicate the presence of the tufts (Fig. 
4a) in the non-impacted specimens and the damage created by the $15 \mathrm{~J}$ impact (Fig. 4b) is visualised with the help of image processing software (Fig. 4c).

Standard double cantilever beam (DCB) specimens (BS ISO 15024:2001) were prepared for the evaluation of the delamination propagation resistance of control and tufted coupons. These samples were manufactured from the same materials and by the same manufacturing methods as in the above described tests, with cured plate thickness of $3.35 \mathrm{~mm}$. The first line of tufts had been positioned $15 \mathrm{~mm}$ beyond the edge of the crack starter film. It was subsequently found necessary to use considerably thicker DCB specimens and to reduce the areal density of through-the-thickness reinforcement, in order for the delamination to propagate in the correct plane of the specimen. For these specimens, carbon Sigmatex MC904 quasi-isotropic non-crimped fabric was used, tufted with the glass tufting thread in a $4 \mathrm{mmx} 4 \mathrm{~mm}$ square pattern. Given the size limitations of our RTM tool, these much thicker plates were vacuum infused with a low viscosity three component epoxy resin, to arrive at a cured thickness of $6 \mathrm{~mm}$. It should be noted that, under vacuum infusion process conditions, the local perturbations to fabric permeability become important. The blocks of tufts can cause localised air trapping when the preform is infused by 'in-plane' resin flow but facilitate impregnation via a transverse resin flow. The impregnation conditions have to be carefully controlled to take account of this added complexity.

\section{Results}

The overall quality and the mesostructure of tufted specimens were analysed via optical microscopy of polished cross-sections of the cured composite. The inclination of the tufts remains reasonably orthogonal to the laminate plane after curing, as shown in 
Figures 5a and 5b. The glass thread tuft cross-section (Fig. 5c) is circular whereas in the carbon thread tuft the yarns appear to remain well separated in a 4-lobe shape (Fig. 5d). The total carbon fibre volume fraction of the panels was determined by an acid digestion technique and the average value was $51.5 \%$. In those tensile test specimens tufted with the glass thread, the total theoretical volume fraction of glass was calculated as $7.7 \%$ of the final cured composite. The actual glass fibre content of such tufted specimens, determined from the acid digestion data and the detailed geometry of the specimens, was $7.9 \%$. In terms of the effects on the mechanical properties, it is more correct to consider only the 'functional' portion of glass thread, neglecting the surface stitches and the loops contained in the $300-400 \mu \mathrm{m}$ thick external resin-rich layer. On this basis, the functional glass fibre content drops to $4.4 \%$ of the sample volume, for a $3 \mathrm{~mm} \times 3 \mathrm{~mm}$ tufting pattern.

Figure 6 shows representative stress vs. strain curves of control and glass fibre tufted samples tested in tension. Control samples exhibit a linear response almost to failure. The initial slopes of the two lines are indistinguishable, giving a Young's Modulus of $55 \mathrm{GPa}$, but the behaviour of the tufted sample shows a deviation from linearity at a strain of $0.35 \%$. The ultimate tensile strength of the samples is reduced from $477(+/-$ 25) MPa to $430(+/-16) \mathrm{MPa}$ by tufting. This translates to a $10 \%$ reduction. In the tufted samples the crack always propagates along a line of tufts, transverse to the longitudinal axis of the specimen. Several mechanisms could be responsible for weakening the area around each tuft. Apart from the expected localised breakage of the preform fibres due to the needle penetration itself, post mortem analysis of tested specimens also revealed the presence of small resin pockets and voids around the tufts (Fig. 7). 
The falling weight impact tests recorded in Figure 8 demonstrate that the maximum load experienced during the impact on glass thread and carbon thread tufted samples is increased by $24 \%$ and $28 \%$ respectively when compared to control samples.

The apparent total extent of the damage in the central region of the specimen does not change significantly between the control and the tufted samples. However, analysis of the images obtained by processing the $\mathrm{C}$-scan patterns reveals that delamination in the control samples usually propagates along the main directions of the fabric fibres $\left(0^{\circ} / 90^{\circ}\right)$, giving a characteristic and well defined cross shape to the damage region (see Fig. 4.e), whilst in the case of tufted samples the shape of the damage area is more circular and fewer delaminated planes are observed. Accordingly, the CAI strength of these samples is increased by $25 \%$ and $27 \%$ in the presence of a central tufted block, using glass and carbon threads respectively (see Table 2).

In the $3.35 \mathrm{~mm}$ thick DCB samples the delamination did not propagate into the tufted region, instead the specimens failed by flexural failure of the beam arms. It was also impossible to propagate the centre plane delamination when the equivalent samples were stiffened by bonding of $6 \mathrm{~mm}$ thick aluminium sheets on each side.

In the case of the $6 \mathrm{~mm}$ thick NCF based samples two of the tufted specimens still failed by breakage of the beam arms, but from the remaining samples it was possible to obtain a quantified comparison of the delamination resistance curves under Mode I loading for control and tufted samples (see Fig. 9). There was no evidence of tuft pull-out during the test and subsequent examination of the fracture surfaces showed broken tufts.

\section{Discussion and Conclusions}

The technique of robotic reinforcement of dry carbon fabric stacks by glass or carbon fibre threads has proved to be relatively easy to introduce in the laboratory environment. 
Apart from the issues of interfacing and programming of the robot arm and the commercial tufting head, the major practical challenges are in ensuring sufficient anchorage of the tuft loops on the underside of the tufted preform and in avoiding frequent thread breakage. The latter is achieved by initial selection of a suitable thread, coupled with suitable selection of the needle eye shape and a suitable tufting speed. Less frequent thread breakage is observed at higher tufting speeds. The observed reduction in the ultimate tensile strength of the tufted samples is a measure of the extent of fibre damage caused by the tufting process; in our particular case a drop of $10 \%$ of the original strength for the addition of 4 to $5 \%$ by volume of 'functional' glass tufting thread in the z-direction. This reduction in the in-plane strength is comparable to what has been observed in Z-pinned laminates $[17,18]$. However, the values quoted here cannot be expected to be a universal quantification of the effect for tufted composites as this is likely to be dependent on the thread size and type, pattern grid, nature of the fabric, level of binder used, size of the needle and the tufting speed.

A drop-down in tensile stiffness of some 5\% might also have been expected, based on simple 'dilution' effect of the presence of the Z-direction reinforcement [18]. This has not been detected within experimental error. As shown in Figure 6, after the initial coincidence with the control sample data, the stress-strain curve for the tufted composite becomes non-linear at a tensile stress of about 150MPa. This effect is not found with the control material. It is interesting to note that this non-linear behaviour has also been observed at about the same stress level in the tensile stress-strain curves for 3D woven composites with through-the-thickness reinforcement. The deflection of the curve is 
attributed to plastic straightening of load-bearing tows that have been crimped by the through-thickness reinforcement [19,20].

As in Z-pinned laminated samples $[17,18]$ the presence of the tufts would be expected to increase significantly the resistance to propagation of a delamination crack in our samples. The significant increase in the CAI performance of the tufted samples must, in part, be due to the increased resistance to delamination. Our initial crack opening mode delamination tests did not provide any useful data, apart from demonstrating just how much stronger the tufted samples are. It was necessary to increase the tuft-to-tuft spacing from 3 to $4 \mathrm{~mm}$ and use a $6 \mathrm{~mm}$ thick specimen before valid Mode I delamination failures were obtained. For the particular specimen configuration used, the presence of this local reinforcement results in an order of magnitude increase in the delamination propagation resistance.

The early investigation presented here indicates an attractive balance of mechanical performance in the tufted composite samples which is comparable to, and possibly superior to, the performance achievable by Z-Fibre® pinning of prepreg laminates $[5,7,17]$. It remains to be clarified what damage resisting mechanisms are responsible for the significant delamination suppression in the tufted specimens, especially noting the apparent absence of tuft pull-out from the laminates. In Z-pinned composites the frictional pull-out of the Z-pins is a major energy absorbing mechanism, accounting for their crack bridging action under crack opening displacement.

The question of how to deal with the external loops of thread produced by the tufting process is unique to this technology. If, as in this work, the loops are left and 
subsequently impregnated by resin, then any mechanical properties measured necessarily become sample specific. As with other forms of Z-direction reinforcement, it is important to realise that the absolute value of the change in any given mechanical property, as a result of tufting, will be a function of the specimen geometry as well as of the tufting parameters. Future parametric studies, such as effects of tuft type, size, spacing, overall sample geometry and even eventual structural response, will probably best be carried out via carefully validated modelling. To this end work has started on the development of suitable models, along the same principles as modelling methods previously applied successfully to Z-pinned composites [21,22].

\section{Acknowledgements}

The study presented here was funded by EPSRC via Cranfield University IMRC and by BAE SYSTEMS (CAFV Programme). The authors are grateful for the gifts of raw materials by VT Halmatic and Cytec Engineered Materials.

\section{References}

1. Sickinger C, Herrmann A. Structural stitching as a method to design high-performance composites in future. Available on line: http://www.dlr.de/fa/en/PortalData/17/Resources/dokumente/institut/2001/2001_03.pdf

2. Wittig J. In-mold-reinforcement of preforms by 3-dimensional tufting. In: 47th International SAMPE Symposium and Exhibition Proceedings. Long Beach, May, 2002. p. 1043-1051.

3. Wittig J. Recent development in the robotic stitching technology for textile structural composites. Journal of Textile and Apparel, Technology and Management 2001; 1(2): $1-8$.

4. Farley GL, Dickinson LC. Removal of surface loop from stitched composites can improve compression and compression-after-impact strengths. J Reinf Plast Compos 1992; 11 (6): 633-642.

5. Cartié DDR, Dell' Anno G, Poulin E, Partridge IK. 3D reinforcement of stiffener-to-skin T-joints by Z-pinning and tufting. Eng Fract Mech 2006; 73 (16): 2532-2540. 
6. Mouritz AP, Leong KH, Herszberg I. A review of the effect of stitching on the in-plane mechanical properties of fibre-reinforced polymer composites. Composites Part A 1997; 28 (1): 979-991.

7. Tong L, Mouritz AP, Bannister M. 3D Fibre Reinforced Polymer Composites. Oxford: Elsevier, 2002.

8. Cox BN, Massabò R, Kedward KT. Suppression of delaminations in curved structures by stitching. Composites Part A 1996; 27 (12): 1133-1138.

9. Dransfield KA, Jain LK, Mai YW. On the effects of stitching in CFRPs-I. Mode I delamination toughness. Compos Sci Technol 1998; 58 (6): 815-827.

10. Jain LK, Dransfield KA, Mai YW. On the effects of stitching in CFRPs-II. Mode II delamination toughness. Compos Sci Technol 1998; 58 (6): 829-837.

11. Potluri P, Kusak E, Reddy TY. Novel stitch-bonded sandwich composite structures. Compos Struct 2003; 59 (2): 251-259.

12. Suh SS, Han N, Yang JM, Hahn HT. The effect of stitching on damage tolerance of stiffened composite panel. Available on line:

http://alpha.tamu.edu/public/temp/asc17/153.pdf

13. Sun X, Tong L, Wood MDK, Mai YW. Effect of stitch distribution on mode I delamination toughness of laminated DCB specimens. Compos Sci Technol 2004; 64 (7-8): 967-981.

14. Schneider M. Carbon-fibre sewing yarn for composites. JEC Composites 2006; 24: 63-65.

15. Partridge IK, Cartié DDR. Delamination resistant laminates by Z-Fiber® pinning. Part I Manufacture and Fracture Performance. Composites Part A 2005; 36 (1): 55-64.

16. LIMESS Gmbh. http://www.limess.com

17. Partridge IK, Cartié DDR, Bonnington T. Manufacture and performance of Z-pinned composites. In: Advani S, Shonaike G, editors. Advanced Polymeric Materials: Structure-property relationships. Boca Raton: CRC Press, 2003. p.103-138.

18. Grassi M, Zhang X, Meo M. Prediction of stiffness and stresses in Z-fibre reinforced composite laminates. Composites Part A 2002; 33 (12):1653-1664.

19. Cox BN, Dadkhah MS, Morris WL and Flintoff JG. Failure mechanisms of 3D woven composites in tension, compression, and bending. Acta Metal et Mat1994; 42 (12): 3967-3984. 
20. Callus PJ, Mouritz AP, Bannister MK and Leong KH. Tensile properties and failure mechanisms of 3D woven GRP composites. Composites Part A 1999; 30 (11):

1277-1287.

21. Allegri G, Zhang X. On the delamination and debond suppression in structural joints by Z-fibre pinning. Composites Part A 2007; 38 (4): 1107-1115.

22. Cartié DDR, Partridge IK. Prediction of the delamination behaviour of Z-Fiber ${ }^{\circledR}$ reinforced laminates. In: 44th AIAA/ASME/ASCE/AHS/ASC Structures, Structural Dynamics and Materials Conference. Norfolk, Virginia, April, 2003. p.707-712. 


\section{Figures}

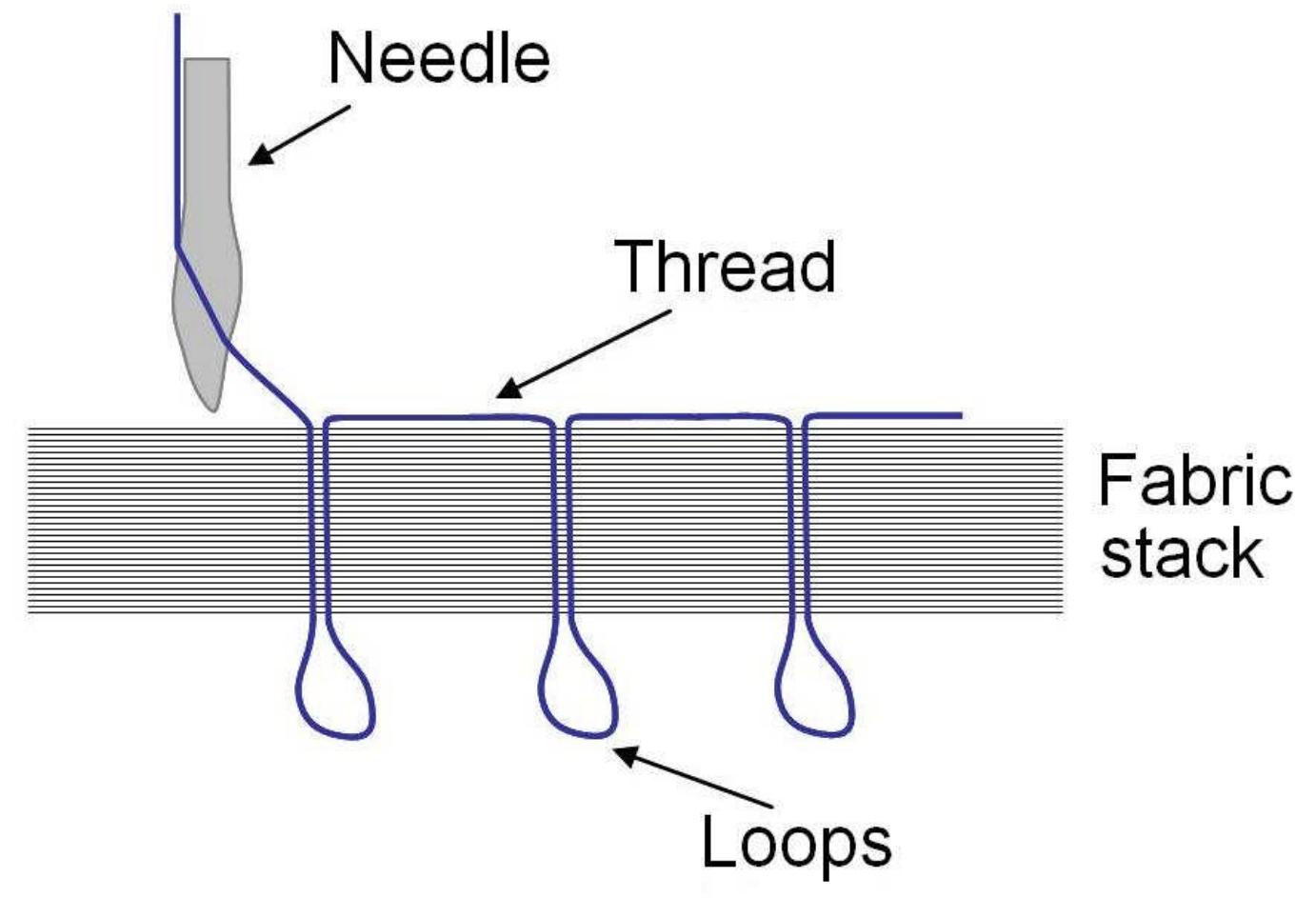

Figure 1: Schematic of the thread arrangement in a tufted preform 


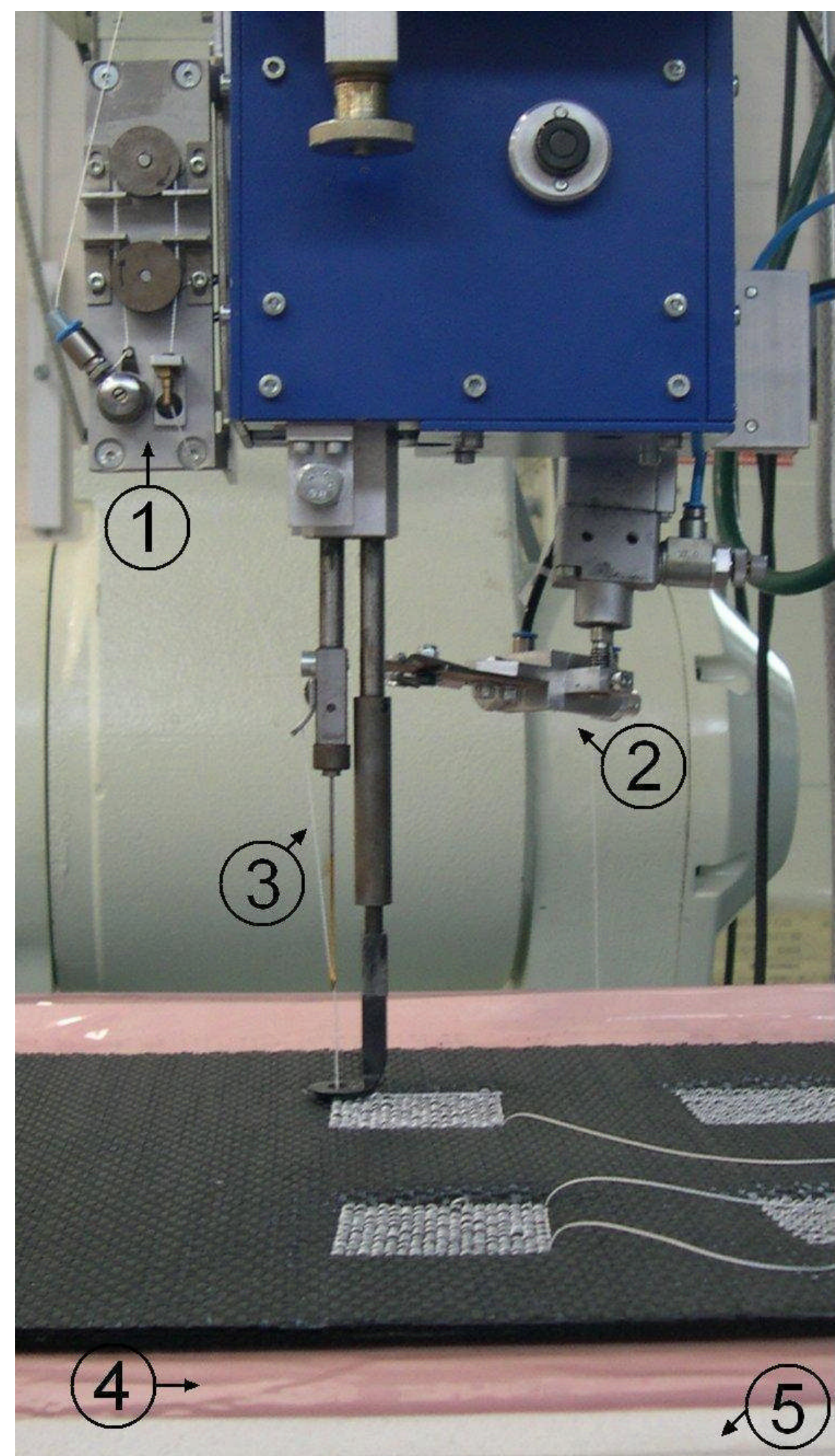

Figure 2: Detail of the KSL KL150 tufting head in operation showing: (1) thread feeding system, (2) pneumatic scissors, (3) tufting needle, (4) nylon film and (5) silicone foam layer. 

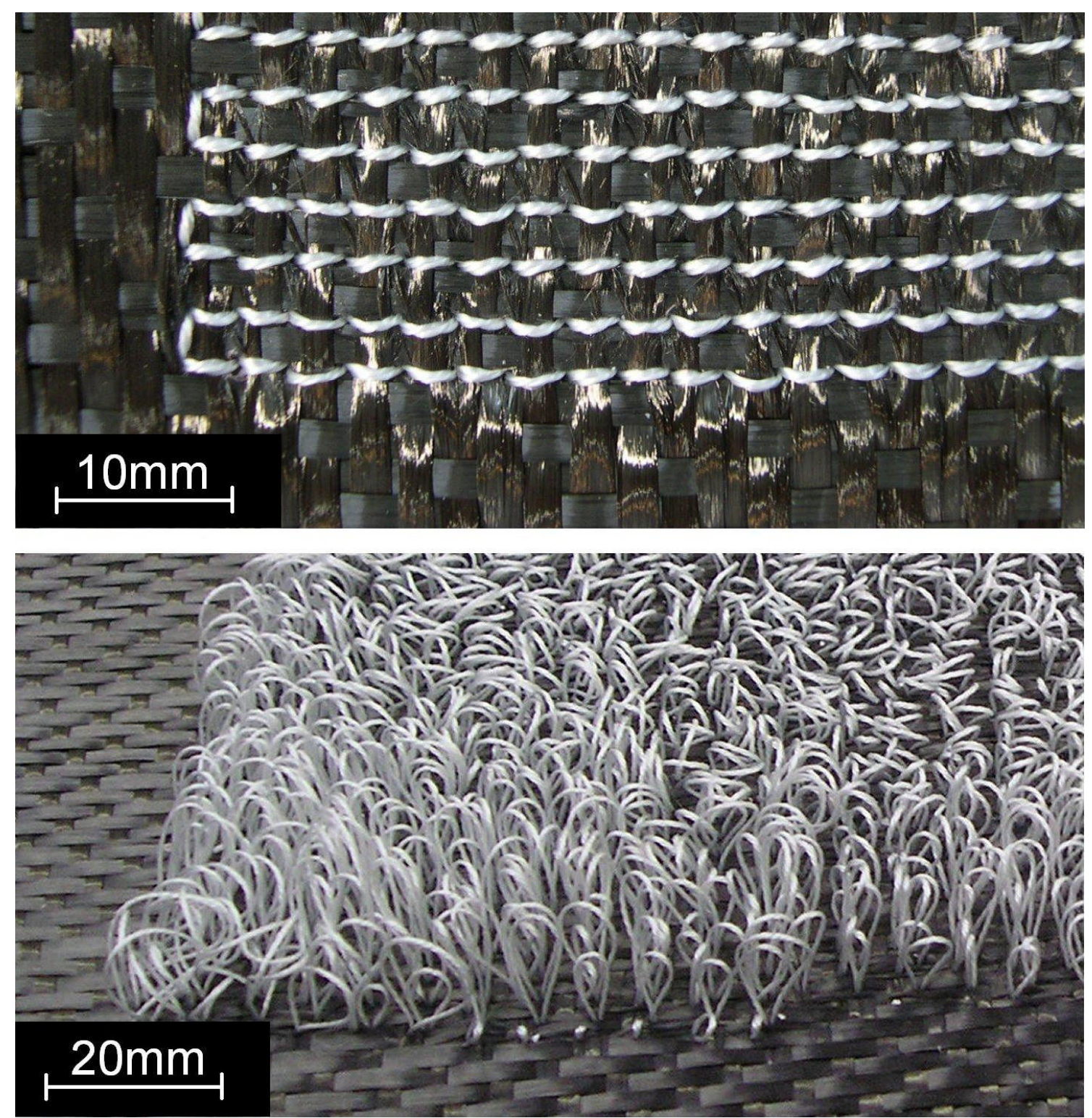

Figure 3: Top-side and under-side view (showing the loops) of a region of 5HS carbon fibre preform, tufted with glass fibre thread in a $3 \mathrm{mmx} 3 \mathrm{~mm}$ pattern. 

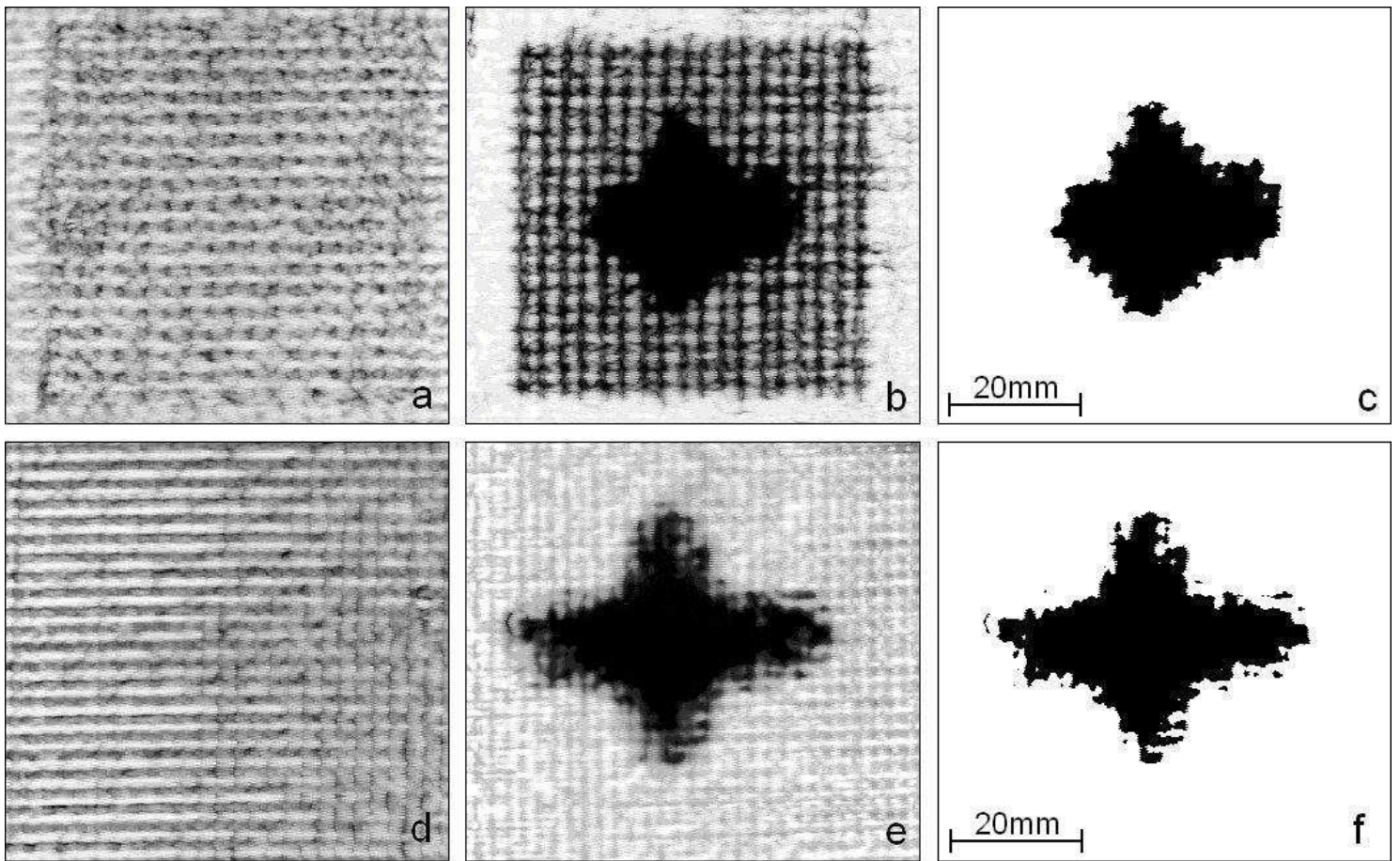

Figure 4: C-scans of the central area of a CAI specimen. The top row of pictures refer to a tufted sample: (a) central $50 \mathrm{~mm} \times 50 \mathrm{~mm}$ area tufted with a $3 \mathrm{~mm} \times 3 \mathrm{~mm}$ pattern before impact, (b) after impact and (c) processed image. The bottom row refers to a control sample: (d) central area of the specimen before impact, (e) after impact and (f) processed image. 

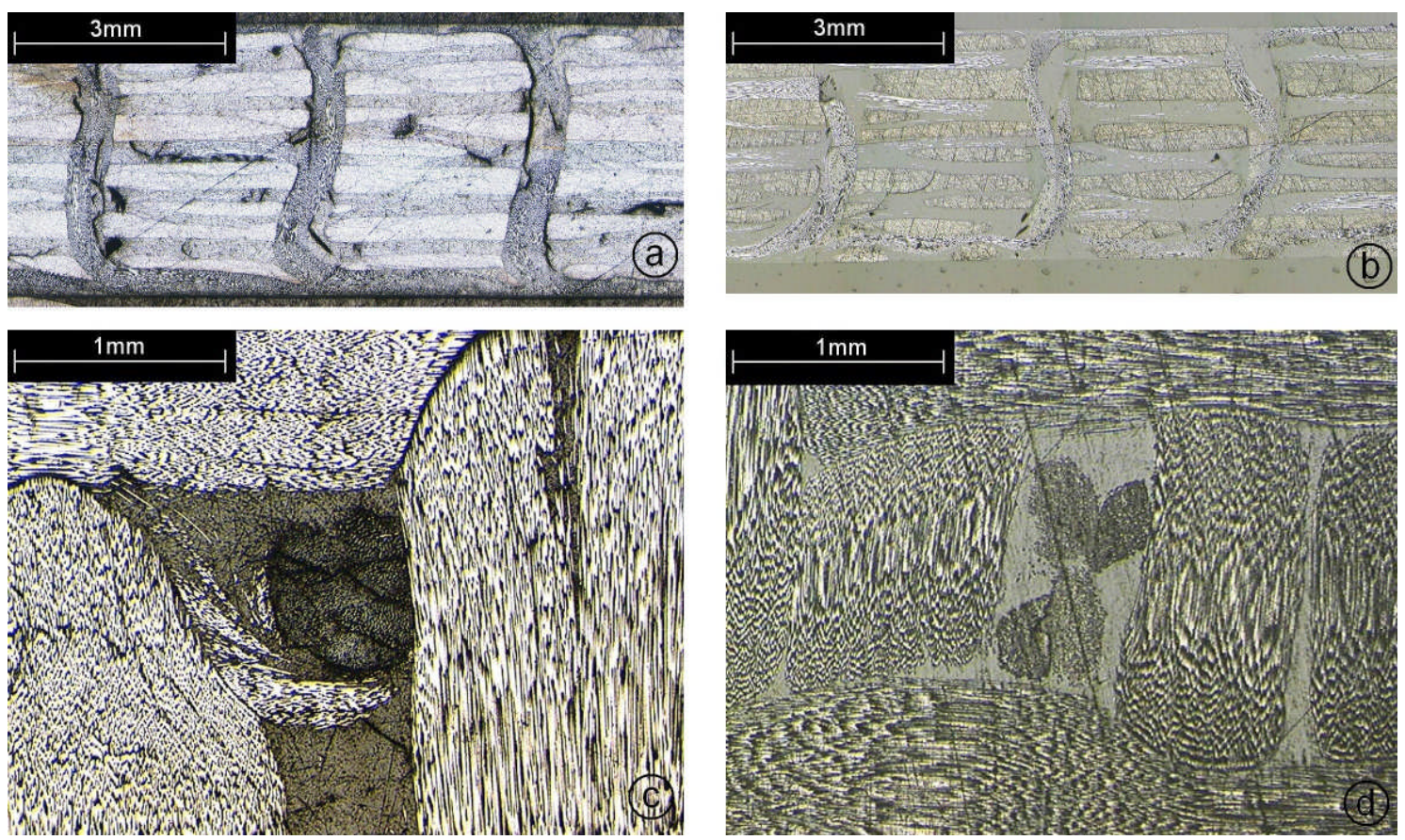

Figure 5: Micrographs of tufted samples showing the longitudinal section of (a) glass fibre thread and (b) carbon fibre thread tufts and the cross section of a single tuft of (c) a glass fibre and $(\mathrm{d})$ a carbon fibre. 


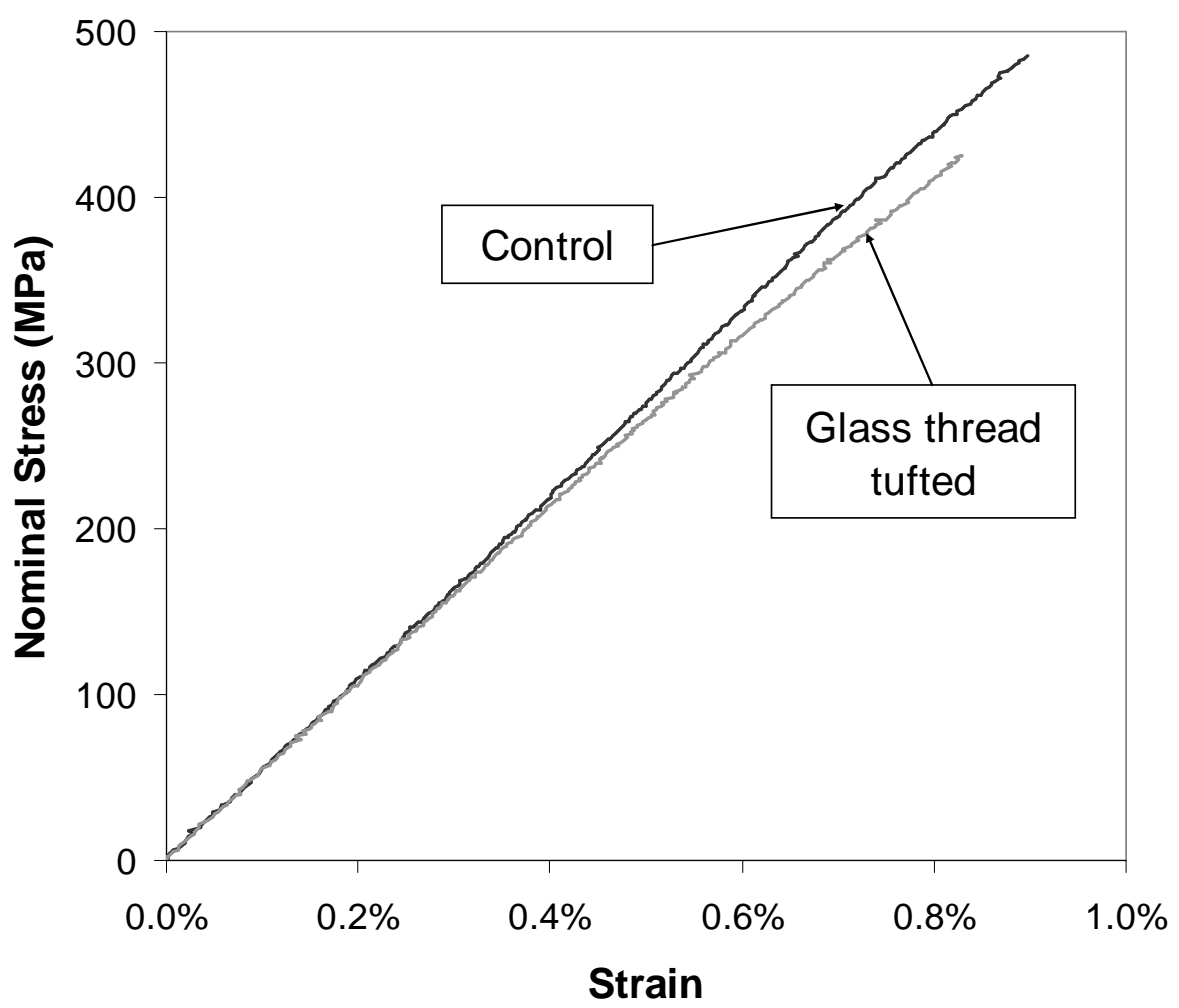

Figure 6: Representative stress-strain plots for control and for glass fibre thread tufted samples tested in tension. 

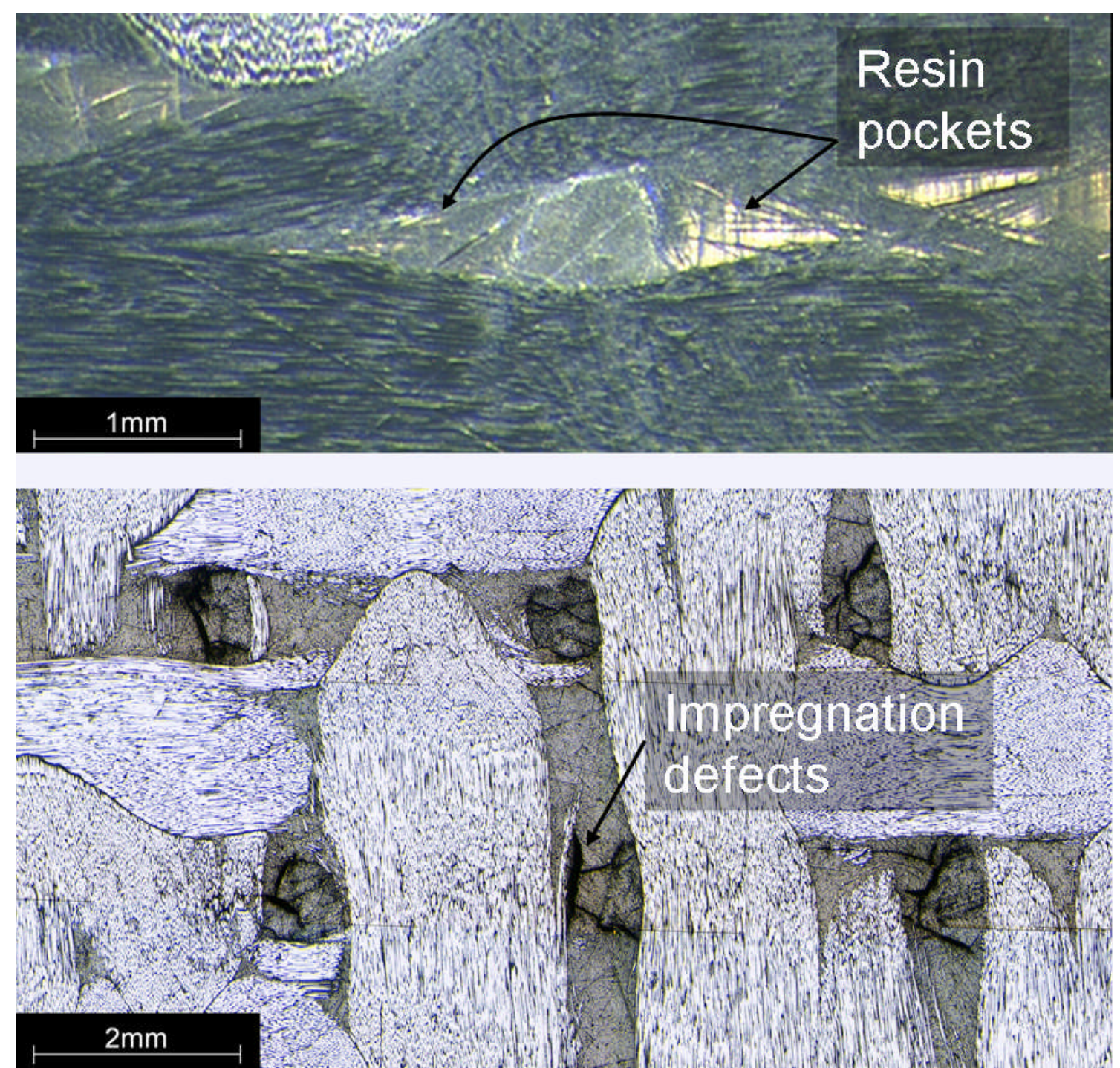

Figure 7: Resin pockets and impregnations defects in a glass thread tufted composite 


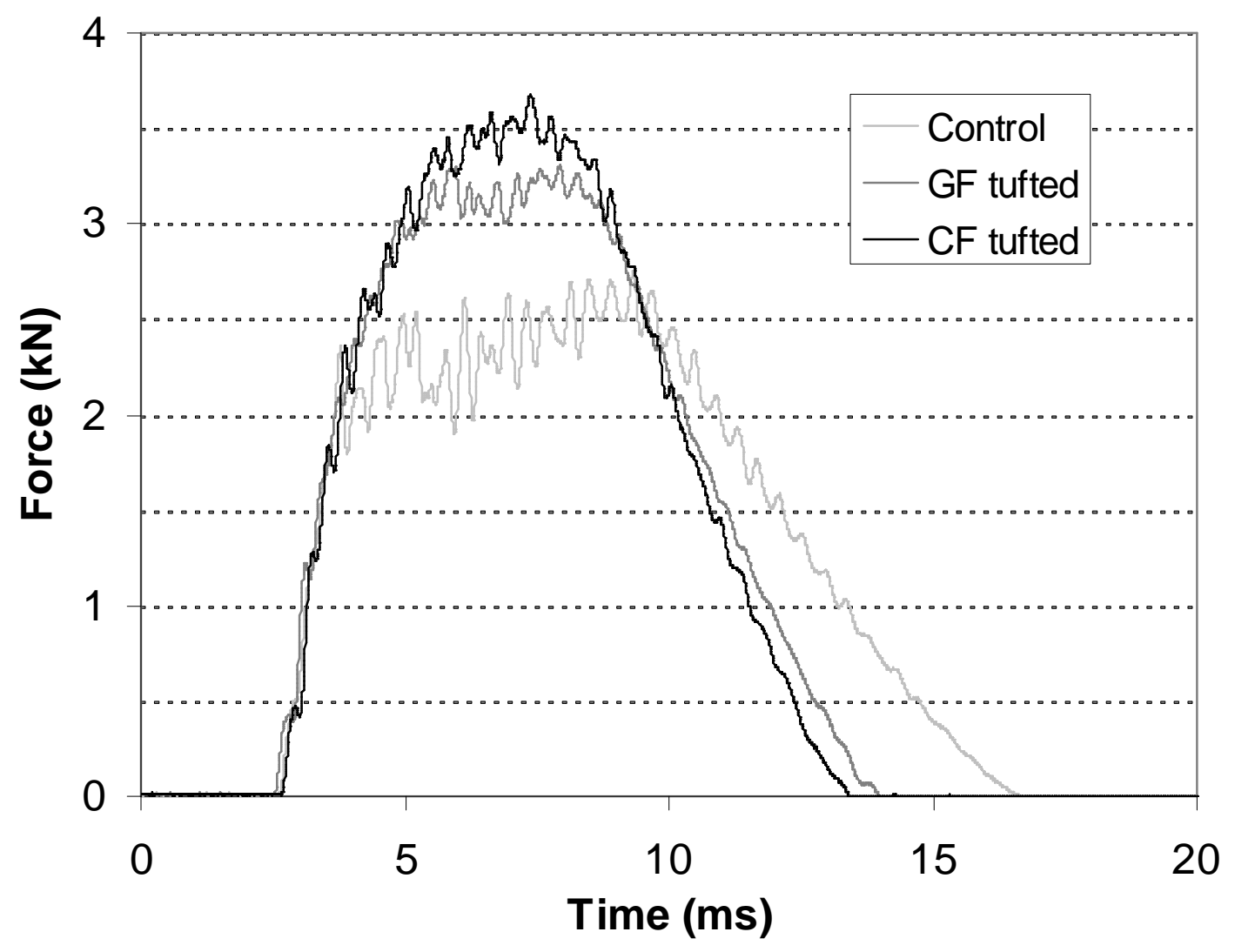

Figure 8: Representative load vs. time curves recorded during impact at $15 \mathrm{~J}$ for control, glass thread and carbon thread tufted specimens. 


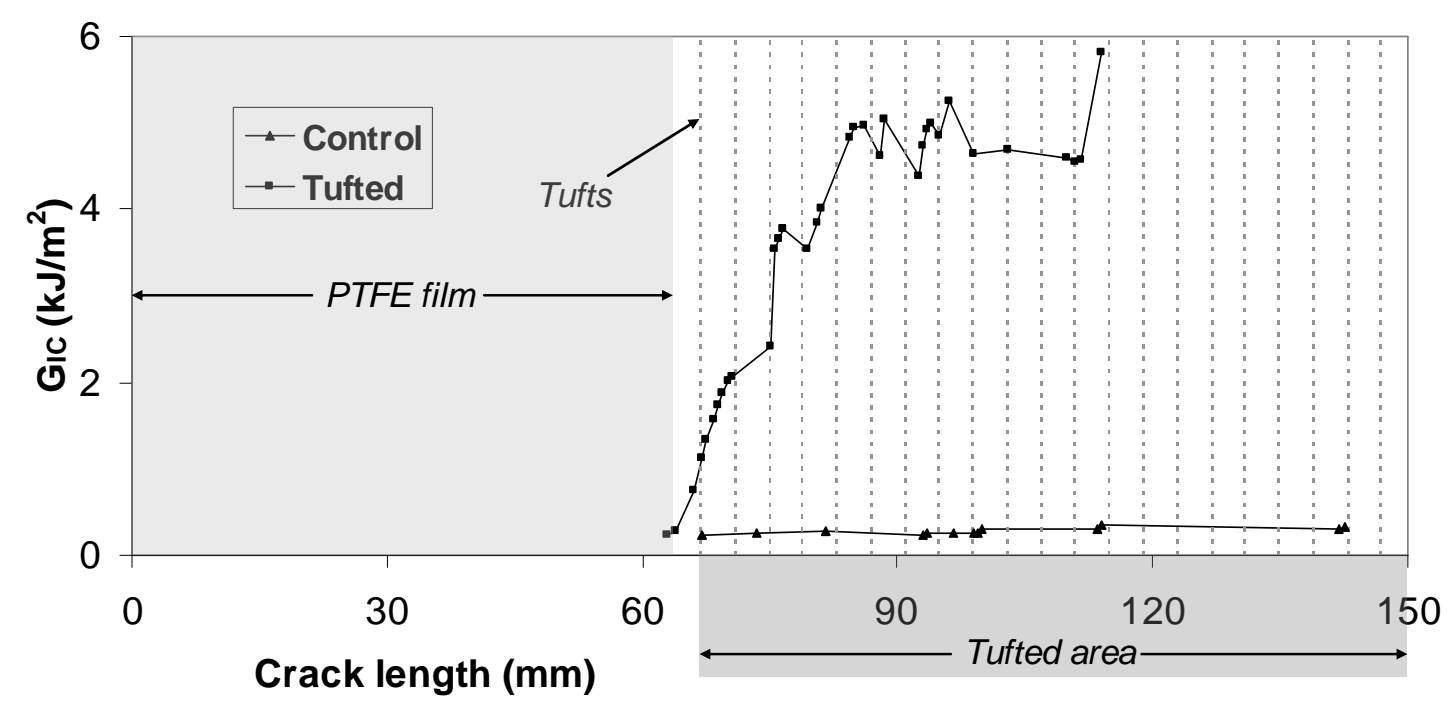

Figure 9: Representative R-curves from Mode I test on DCB samples made of NCF fabric control and an equivalent sample tufted with the glass thread in a $4 \mathrm{mmx} 4 \mathrm{~mm}$ square pattern. Fibre volume fraction is $55 \%$. 


\section{Movie}

Movie 1: KSL KL150 tufting head installed on a Kawasaki FS 20N robot arm in operation

(The movie file will be sent to the editor separately.) 


\section{Tables}

Table 1: Attributes of the commercial tufting threads used

\section{Glass fibre thread}

Material

Specific weight

Filament count

Filament diameter

Max load

(unimpregnated)
EC $968 \times 3$ S260 T8G

Saint Gobain ${ }^{\circledR}$ Vetrotex ${ }^{\circledR}$

$204 \mathrm{~g} / \mathrm{km}$

$204(3 \times 68)$

$9 \mu \mathrm{m}$

$93 \mathrm{~N}$
Carbon fibre thread

Tenax ${ }^{\circledR}$

HT Sewing Yarn

$137 \mathrm{~g} / \mathrm{km}$

$2000(2 \times 1000)$

$7 \mu \mathrm{m}$

$139 \mathrm{~N}$ 
Table 2: Impact and Compression after Impact behaviour of control, glass thread and carbon thread tufted specimens

\begin{tabular}{ccccc} 
& $\begin{array}{c}\text { Maximum load during impact } \\
\text { Coefficient of } \\
\text { variation }\end{array}$ & MPa & $\begin{array}{c}\text { CAI strength } \\
\text { Coefficient of } \\
\text { variation }\end{array}$ \\
\hline Control & 2710 & $1.9 \%$ & 162 & $3.0 \%$ \\
GF tufted & 3371 & $1.4 \%$ & 203 & $5.2 \%$ \\
CF tufted & 3455 & $5.5 \%$ & 205 & $2.8 \%$
\end{tabular}

